\title{
Biblioteca Pública Estadual de Minas Gerais: percurso histórico e dinâmicas de inserção social
}

\author{
Public State Library of Minas Gerais: historical path and dynamics of social insertion
}

\begin{abstract}
Fabrício José Nascimento da Silveira
Doutor em Ciência da Informação pela Universidade Federal de Minas Gerais - UFMG.

Professor adjunto da Escola de Ciência da Informação da Universidade Federal de Minas Gerais - UFMG.

E-mail: fabrisilveira@gmail.com
\end{abstract}

\section{Resumo}

O presente trabalho objetiva refletir sobre duas questões centrais: qual o lugar ocupado pela Biblioteca Pública Estadual de Minas Gerais no cenário cultural e intelectual de Belo Horizonte? Em que medida a apropriação de seus acervos e serviços, bem como as dinâmicas de sociabilidade experienciadas em seus espaços marcam a história de vida dos usuários que a ela recorrem? Para tanto, em um primeiro momento, traça-se, por meio de pesquisa bibliográfica, um panorama histórico dessa unidade bibliotecária, destacando-se acontecimentos relevantes em sua trajetória e evidenciando os principais serviços e atividades oferecidos à população belohorizontina, bem como a diversidade de suas coleções. Posteriormente, e visando-se apreender a importância da Biblioteca para a cidade e para seus usuários, analisa-se as respostas conferidas por 4 sujeitos às seguintes indagações: que impressões e sensações foram vivenciadas por eles durante o primeiro contato com a Biblioteca Estadual? Qual a importância da Biblioteca para Belo Horizonte; e qual o lugar que a mesma ocupa em suas histórias de vida? Como resultado, além de demarcar a importância social da instituição e os modos como intervém na paisagem cultural de Belo Horizonte e do estado, ressalta-se a relevância simbólica e afetiva que ela possui para cada um de nossos depoentes.

Palavras-Chave: Biblioteca pública. Biblioteca Pública Estadual de Minas Gerais. Biblioteca Pública Estadual de Minas Gerais - história. Biblioteca Pública Estadual de Minas Gerais - função social. História Oral.

\begin{abstract}
The following project aims a reflection on two main issues: What is the place occupied by the State Public Library of Minas Gerais in Belo Horizonte's cultural and intellectual scene? To what extent do the appropriation of their collections and services, as well as the dynamics of sociability experienced in their spaces, mark the life history of their users? To do so, at first, by means of bibliographical research, a historical panorama of this library unit is outlined, highlighting important events in its trajectory and emphasizing the main services and activities offered to the population of Belo Horizonte, as well as the diversity of its collections. Subsequently, in order to understand the importance of the Library for the city and its users, four subjects were asked the following questions: what impressions and sensations have they experienced during the first contact with the State Library? How important is the Library to Belo Horizonte; and what place does it occupy in their life stories? Then, the answers given by them are analyzed. As a result, in addition to demarcating the social importance of the institution and the ways in which it operates in the cultural landscape of Belo Horizonte and the state, the symbolic and affective relevance that it has for each one of our deponents is pointed out.
\end{abstract}

Keywords: Public library. State Public Library of Minas Gerais. State Public Library of Minas Gerais - history. State Public Library of Minas Gerais - social function. Oral History. 


\section{Introdução}

Em julho de 1954 o então governador de Minas Gerais, Juscelino Kubitschek, sancionou a Lei 1087, cujo objetivo principal era criar a Biblioteca Pública de Minas Gerais. Segunda instituição do tipo na capital mineira, esperava-se que a mesma oferecesse a estudantes e pesquisadores a documentação necessária aos seus trabalhos; mantivesse serviços de extensão bibliotecária e cultural, franqueados ao público; e, que cooperasse com a criação e manutenção de bibliotecas e salas de leitura públicas no interior do Estado. Seguindo essas diretrizes e incorporando as aspirações "modernistas" que vigoravam em Belo Horizonte àquela época, a Biblioteca Pública ganhou sede própria, teve suas coleções significativamente ampliadas e novos serviços projetados.

Em 1961 foi rebatizada, passando a denominar-se Biblioteca Pública Estadual Luiz de Bessa. Além desse fato, a década de 1960 marca de vez sua inserção no cenário social e intelectual da cidade, uma vez que nesse período são idealizados importantes serviços que ainda hoje se encontram à disposição da população, tais como o carro-biblioteca, o setor braile, sua divisão infanto-juvenil e também o serviço de caixa-estante. Outro ponto relevante de sua trajetória histórica foi a criação da Superintendência de Bibliotecas Públicas, cujos objetivos principais eram ampliar e coordenar a atuação das demais bibliotecas públicas do Estado. Com isso, a instituição se converte em ponto de referência cultural dos mineiros, não só em função das ações que desenvolve em prol da preservação e difusão da memória e da identidade do Estado, mas, sobretudo, por sua atuação educacional e nas áreas de promoção da leitura, da disseminação da informação, da democratização do conhecimento e do fomento às artes e ao lazer.

Foi, pois, atentando para tais aspectos, sobretudo aquele que se refere às suas potencialidades representacionais e seu caráter de "memória viva do estado" que a biblioteca teve seu nome alterado mais uma vez, voltando a ser denominada, em maio de 2017, como Biblioteca Pública Estadual de Minas Gerais. Mais que recobrar suas disposições iniciais de atuação, essa mudança deixa claro o entendimento do significado geral da instituição tanto para Belo Horizonte quanto para o Estado, que agora a define como "casa mater das bibliotecas mineiras [cuja] referência cultural honra nosso Estado". (OSWALDO, 2017).

De fato, mais que atender às necessidades de leitura, educação e lazer de seus usuários, a Biblioteca Pública Estadual converte-se em marco de representação local, tanto em nível coletivo 
- é um lugar de memória ${ }^{1}$ e de mobilização da cultura mineira -, quanto em sua dimensão intersubjetiva, uma vez que as experiências vivenciadas pelos sujeitos que a ela recorrem, seja para uso de seus espaços e coleções ou no nível das relações interpessoais, acaba por converterse em instância de ancoragem do conjunto de referências que alimenta, reforça e modula seus discursos identitários.

Nesse sentido, e atentando para tais aspectos, o que pretendemos apontar aqui são os vários elementos que nos permitem demarcar o lugar social ocupado pela Biblioteca Pública Estadual de Minas Gerais tanto para a comunidade que ela atende quanto para alguns sujeitos específicos. Para tanto, definem-se duas estratégias metodológicas complementares: em um primeiro momento, traça-se um panorama histórico dessa unidade bibliotecária, destacando-se acontecimentos relevantes em sua trajetória e evidenciando os principais serviços e atividades oferecidos à população belo-horizontina, bem como a diversidade de suas coleções ${ }^{2}$. Posteriormente, analisam-se as respostas conferidas por quatro (4) sujeitos às seguintes indagações: que impressões e sensações foram vivenciadas por eles durante o primeiro contato com a Biblioteca Estadual? Qual a importância da Biblioteca Pública para Belo Horizonte; e qual o lugar que a mesma ocupa em suas histórias de vida?

Colhidos como parte de uma pesquisa de doutoramento ${ }^{3}$, a amostra total dos depoentes ${ }^{4}$ foi definida intencionalmente após prolongada imersão no cotidiano da Biblioteca Pública ${ }^{5}$ e de conversas com seus bibliotecários e leitores. Para tanto, levou-se em consideração os seguintes

\footnotetext{
${ }^{1}$ Expressão tradicionalmente associada à coletânea Les lieux de mémoire, organizada pelo historiador francês Pierre Nora entre os anos de 1984 e 1992, que adotou para si a tarefa de demonstrar que o movimento de socialização dos repertórios mnêmicos na contemporaneidade está diretamente relacionado à sua força de impregnação em marcos físicos e simbólicos que acabam por promover uma espacialização tanto da memória quanto da identidade, inserindo-se assim no âmbito das estratégias de reivindicação por um complexo direito ao reconhecimento de si. Para além disso, este empreendimento demonstra, ainda, que entender os "lugares de memória" como manifestações de um acontecimento ou de uma lembrança cristalizada no tempo não é suficiente se não se leva em consideração os usos e os contra-usos que a dinâmica social lhes impõe. Sendo mais preciso: que arquivos, museus, bibliotecas, monumentos, símbolos e datas nacionais, festas comemorativas, santuários e coleções são lugares de memória cujo referencial mnêmico-identitário nasce e se instaura em um campo de batalhas onde o presente se debate com o passado como artifício para se edificar um futuro modulado e atravessado por ressonâncias coletivas, por isso sua força política, ideológica, histórica, cultural e de identificação coletiva. Dialogando com as ideias de Pierre Nora, os trabalhos de Cesarino (2006) e Silveira (2014) analisam, por meio de dois caminhos teórico-metodológicos distintos, os vários elementos simbólicos, culturais e intersubjetivos que fazem da Biblioteca Pública Estadual de Minas Gerais um "lugar de memória" para os mineiros.

${ }^{2}$ Essa primeira estratégia adotou como aporte principal os trabalhos de Cesarino (2006) e Bretas (2010), bem como as distintas leis e decretos mencionados ao longo do texto.

${ }^{3}$ Conferir Silveira (2014).

${ }^{4}$ Para a tese entrevistamos 7 sujeitos, 5 homens e duas mulheres. Em função das limitações de espaço, efetuamos no contexto do presente trabalho um recorte dessa amostra total.

${ }^{5}$ Visando-se identificar os possíveis participantes da pesquisa, frequentamos a instituição por um (1) mês. Por vezes a permanência na Biblioteca Estadual se dava ao longo de todo o dia, em outras em turnos distintos. $\mathrm{O}$ objetivo dessa ação era participar das atividades e do cotidiano da instituição e criar empatia com nossos depoentes.
} 
critérios: tempo em que o entrevistado é usuário da instituição, frequência com que utiliza ou participa das ações por ela desenvolvidas, e, principalmente, o reconhecimento por parte dos próprios sujeitos de que a Biblioteca Estadual se constitui como referência marcante em sua história de vida. Além desses, dois outros critérios foram levados em consideração: os testemunhantes selecionados deveriam representar a diversidade de indivíduos que usam os distintos setores da Biblioteca e, para não se correr o risco de, ao final do trabalho, consolidarmos um discurso unificado e pacificado sobre as proposições aqui tratadas, pelo menos um dos depoentes deveria se declarar alheio a essa afetação, ou seja, apontar que a Biblioteca Pública Estadual não se consolida como um referente importante em sua história de vida.

Os dados foram coletados mediante a realização de entrevistas semiestruturadas, concedidas em dia e local escolhido pelos próprios depoentes. Em média cada entrevista teve a duração de uma (1) hora, sendo gravada com permissão prévia de nossos interlocutores. Como dispositivo orientador, elaborou-se um conjunto de perguntas que permitiram aos nossos interlocutores refletirem sobre sua formação enquanto sujeitos históricos e sobre as relações que mantém/mantinham com e no espaço público de Belo Horizonte (atividades, estratégias de mobilização e relações prático-afetivas). Possibilitaram ainda, como pode ser observado pelas 3 (três) questões anteriormente apresentadas, que os depoentes analisassem o lugar ocupado pela Biblioteca Estadual - dimensões históricas, simbólicas e estruturais - em todo esse processo formativo-relacional. Dito isso, comecemos por delinear os principais fatos e acontecimentos que particularizam e valorizam socialmente a trajetória histórica dessa instituição. 


\title{
2. Da "Sociedade Literaria Bello Horizonte" à Biblioteca Pública Estadual de Minas Gerais: percurso histórico
}

\begin{abstract}
A história desta Casa não é tranquila e de linear horizontalidade, mas ao contrário, de impulsão e de propulsão contra obstáculos os mais complexos, desde as consideradas naturais deficiências financeiras às tentativas de seu ocultamento ou marginalização. Diante dos empecilhos, do abandono, do desprestígio, da omissão e de entraves de toda ordem, o lema da Biblioteca, impresso em cada pequena tarefa de seus diretores e funcionários, tem sido o de ir sempre em frente, ainda quando parece não haver saída. (ARAÚJO, 1984 apud CESARINO, 2006, p.35).
\end{abstract}

Até a inauguração da Biblioteca Pública de Minas Gerais, Belo Horizonte possuía apenas uma biblioteca pública. Subordinada à Prefeitura Municipal e localizada na Rua da Bahia, esquina com a Avenida Augusto de Lima, a mesma havia sido criada seguindo os auspícios de "modernidade" que orientou a construção da nova capital mineira entre os anos de 1893 a 1897. De acordo com Abílio Barreto:

Cinco mezes apenas eram decorridos após o início dos trabalhos da Commissão Constructora da Nova Capital em Bello Horizonte, quando alguns dos mais brilhantes membros desta, entre os quaes os drs. Fabio Nunes Leal, Samuel Gomes Pereira, Americo de Macedo e José de Magalhães, em uma concorrida reunião realizada no Escriptorio Central, deliberaram fundar a "Sociedade Literaria Bello Horizonte", com a finalidade de se organizar uma bibliotheca e um museu ${ }^{6}$. (BARRETO, 1935, p. 5).

Tendo Aarão Reis como presidente honorário e adotando por modelo os padrões característicos da biblioteconomia norte-americana, a "Sociedade Literaria de Bello Horizonte" desenvolveu suas primeiras atividades em uma velha casa no Largo da Matriz da Boa Viagem. À época de sua implementação, já contava com um acervo de aproximadamente 4000 títulos, em sua maioria doados pelos próprios membros da Comissão. Além de livros, seu fundo bibliográfico era composto por grande número de revistas e periódicos técnico-científicos relativos às áreas de arquitetura, engenharia e ciências naturais. Segundo Brettas (2010, p.95), a maioria deles, $58 \%$, era de origem francesa, $25 \%$ eram escritos em idioma inglês, e 12,5\% em alemão, e apenas um periódico estava escrito em português. Condição que demonstra, além da influência dos Estados Unidos, uma forte ligação com as correntes ideológicas em vigor na Europa, sobretudo na França. Aponta, também, para a constituição de um espaço de sociabilidade e de representação da elite econômica e política responsável por "conferir ares de civilidade" ao novo arraial. É o que atesta Barreto (1935), ao afirmar que:

\footnotetext{
${ }^{6}$ Por se tratar de um testemunho histórico, optou-se por manter a grafia e as construções linguísticas da época em que o texto foi publicado.
}

InCID: R. Ci. Inf. e Doc., Ribeirão Preto, v. 9, n. 1, p. 146-167, mar./ago. 2018. 
Installada a bibliotheca, possuindo já numerosos e bons livros doados pelos sócios e adquiridos por compra, era aquelle o ponto favorito de reuniões dos funccionarios da Commissão Constructora e demais pessoas cultas do arraial. Era alli que ellas descansavam o espírito em leituras de livros, revistas e jornaes, todas as noites, até a inauguração da cidade, quando se extinguiu a Commissão Constructora. (BARRETO, 1935, p. 7).

Ao término dos trabalhos da comissão, a biblioteca foi doada à prefeitura, que a transferiu para um edifício provisório situado na Rua da Bahia. Constatada a precariedade da nova sede, sua coleção foi levada, em 1904, para o salão térreo do prédio que acolhia os servidores do Senado. Lá permaneceu por dez anos, até que, em 6 de setembro de 1914, migrou para o palácio do Conselho Deliberativo, edificado na esquina da Rua da Bahia com Avenida Paraopeba (atual Avenida Augusto de Lima), onde resistiu por quase cinco décadas, sendo desativada, conforme Brettas (2010), em 1963.

Dois fatores contribuíram diretamente para a dissolução da Biblioteca Pública de Belo Horizonte. O primeiro deles liga-se à necessidade da Câmara de Vereadores, antigo Conselho Deliberativo, conseguir mais espaço para que os políticos belo-horizontinos pudessem efetuar seus despachos e resoluções. O segundo vincula-se à construção da Biblioteca Pública de Minas Gerais, em 1954. A partir desse momento, a antiga instituição foi perdendo o apoio da prefeitura e, aos poucos, com a diminuição do atendimento ao público, também teve seu prestígio desgastado. Esse quadro se estende até 1963, data que decreta sua completa extinção.

\begin{abstract}
A extinção da Biblioteca Pública de Belo Horizonte se deu, em termos legislativos, em 1963, pela publicação da Lei Municipal $n^{\circ} 1054$, de 7 de novembro, que determinou a transferência do acervo da instituição para o Instituto Municipal de Administração e Ciências Contábeis. Em termos administrativos, a instituição ainda não havia sido extinta; no entanto, sua atuação como biblioteca pública municipal foi praticamente anulada em seu novo local. (BRETTAS, 2010, p.104).
\end{abstract}

Naquilo que concerne à nova biblioteca Estadual, coube à comissão composta por Eduardo Frieiro, Hélio Gravatá, Etelvina Lima e Cacilda Basílio de Sousa Reis, idealizar uma instituição "grande, moderna, dinâmica, condizente com o adiantamento da cidade que caminhava célere para o seu primeiro milhão de habitantes". (CESARINO ${ }^{7}, 2006$, p.21). Conforme já mencionado, a Assembleia Legislativa aprovou, em 2 de junho de 1954, a Lei nº. 1087, criando, assim, a Biblioteca Pública do Estado, que passou a funcionar "em instalações provisórias, com um acervo inicial de 22.000 volumes. Três setores foram definidos como essenciais: a Sala de Empréstimo domiciliar, o Setor de Referência e a Divisão de Processamento Técnico". (CESARINO, 2006, p.23).

\footnotetext{
${ }^{7}$ Grande parte dos dados históricos que apresentaremos a seguir tem como fonte o texto de Maria Augusta da Nóbrega Cesarino (2006), cuja referência completa encontra-se citada na bibliografia.
} 
Para melhor abrigá-la, Juscelino Kubitschek solicitou que seu amigo Oscar Niemeyer planejasse uma sede moderna, à altura das pretensões políticas do governador. O arquiteto traçou o desenho de um edifício de 6 andares, com espaços amplos e muitas janelas. A construção do prédio foi longa e repleta de contratempos. Por falta de recursos financeiros, o desenho original sofreu várias alterações e, três dos seis andares previstos foram cortados. Depois de quase três anos de abandono, o governador José Francisco Bias Fortes conseguiu verbas junto à Diretoria de Esportes, aceitou o corte significativo do projeto e, contando com a mão-de-obra de detentos da Casa de Correção, hoje Penitenciária de Neves, deu a sede por terminada. Em 1961, “para não ceder às inúmeras pressões de diversos setores do Governo que cobiçavam o novo prédio, Bias Fortes ordenou a mudança da Biblioteca para a Praça da Liberdade. 'Mudar Militarmente', foram essas suas palavras. Assim foi feito”. (CESARINO, 2006, p.24).

Nesse mesmo ano de 1961, no dia 17 de janeiro, a Biblioteca Pública de Minas Gerais, por meio do Decreto Lei $\mathrm{n}^{\circ}$. 6140, teve acrescentado à sua denominação oficial o nome do professor "Luiz de Bessa", considerando, de acordo com a disposição legal, "os relevantes serviços prestados por ele à nossa cultura e, notadamente, à Administração Pública do Estado". (CESARINO, 2006, p.24).

Embora os primeiros anos de exercício de suas atividades tenham sido marcadamente conturbados, a década de 1960 foi "particularmente rica no fortalecimento da recém-criada biblioteca". (CESARINO, 2006, p.26). De fato, é neste período que importantes ações são concebidas para que a instituição pudesse se inserir de maneira proeminente na vida social e cultural de Belo Horizonte. A primeira delas foi a implementação do carro-biblioteca, serviço de extensão que, já àquela época, objetivava levar "informação e cultura" aos bairros da região metropolitana da cidade que não possuíam acesso a tais equipamentos culturais, bem como valorizar a leitura, a educação e a cidadania. Nos dias atuais, sua biblioteca móvel permite o acondicionamento de "um acervo aproximado de 3.500 livros, dos mais variados assuntos, entre autoajuda, religião, filosofia, biografias, enciclopédias, dicionários, periódicos (jornais e revistas), entre outros, com ênfase em obras de literatura para adultos, jovens e crianças ${ }^{8}$ ".

Outro marco importante desse período foi a criação, em 1962, da divisão InfantoJuvenil, hoje espaço Lúcia Machado da Biblioteca Infanto-Juvenil (BIJU). Seu objetivo era

8 Informações disponíveis no site da Secretaria de Cultura do Estado de Minas Gerais: http://www.cultura.mg.gov.br/cidadao/servicos/biblioteca/page/1629-carro-biblioteca. 
democratizar o acesso à leitura informativa e de lazer para crianças e adolescentes, razão pela qual, desde sua implementação, coordena atividades recreativas e de caráter educativo-cultural, sendo as mais frequentes a hora do conto e da leitura; oficinas, exposições temáticas e literárias; palestras, bate-papo com escritores e rodas de leitura. A BIJU possui, hoje, aproximadamente 25.000 volumes para empréstimo e consulta local.

O Setor Braille também começou a funcionar nessa década, em 1965. Sua criação está ligada à incorporação ao acervo da Biblioteca Pública de uma coleção de livros que até então pertencia à antiga Feira de Amostras da capital. Em 1969 a seção passou a contar oficialmente com um corpo de copistas e ledores voluntários, criado mediante resolução interna. Atualmente, atende pessoas com deficiência integral e parcial, buscando orientá-las em pesquisas e estudos, bem como permitir que tenham acesso à informação e à literatura de cunho geral, através áudiolivros e em Braille.

Já no final da década de 1960 outra iniciativa seria concretizada visando tornar a Biblioteca Pública um polo de referência da cultura mineira. No dia 5 de agosto de 1969 foi criada a Coleção Mineiriana. Suas normas de desenvolvimento, organização e preservação foram pensadas por uma comissão designada pelo então governador Israel Pinheiro. Ao fim dos trabalhos, fixou-se que o objetivo nuclear da Mineiriana da Biblioteca Pública seria compor um acervo de obras sobre Minas Gerais, sua história, letras, artes e ciências da terra e do homem, além de desenvolver ações em prol da divulgação da cultura do Estado e editar publicações correlatas aos temas em foco. Em seu acervo, destacam-se, entre as obras raras, a primeira edição de Alguma Poesia, de Carlos Drummond de Andrade; de Alvarenga Peixoto, Basílio da Gama, Bernardo Guimarães; de Ephemerides Mineiras, de Xavier da Veiga; da coleção completa do Recreador Mineiro, de 1845; O amanuense Belmiro, de Cyro dos Anjos; de Corpo de Baile, de Guimarães Rosa, com dedicatória a Oscar Mendes; e de História do Brasil, de Murilo Mendes. Por tudo isso é apresentada como "um decisivo instrumento para a compreensão de Minas Gerais, suas especificidades históricas e naturais, sua cultura, seus desafios e possibilidades". (PAULA, 2009, p.18).

Também em 1969, a Biblioteca criou o serviço de caixa-estante, cuja finalidade era "levar a oportunidade de leitura a creches, asilos, prisões e espaços alternativos muito diferentes da Praça da Liberdade". (CESARINO, 2006, p.29). Nos dias atuais, utiliza-se um pequeno móvel de 0,6m de altura e 0,5 de largura, que se desdobra em duas estantes, tendo prateleiras internas para os livros. Seu acervo é composto por cerca de 120 itens, distribuídos entre 
literatura brasileira, estrangeira, infantil, juvenil e autoajuda, selecionados de acordo com o perfil do público a ser atendido. O serviço está disponível apenas a instituições da Região Metropolitana de Belo Horizonte. Em paralelo a essa ação, a Biblioteca iniciou um cursinho pré-vestibular no qual professores de literatura analisavam os títulos exigidos pela Universidade Federal de Minas Gerais, programa que se manteve ininterrupto por mais de 30 anos.

Contudo, se os anos de 1960 foram vigorosos para a Biblioteca Pública Estadual, a década seguinte impôs-lhe uma grave crise técnica e política. Isto porque, de acordo com Cesarino (2006, p.29), na gestão do governador Aureliano Chaves, a instituição perdeu seu nome e sua identidade. De fato, o Decreto Lei $\mathrm{n}^{\circ}$. 19.173, de 9 de maio de 1978, a transformou em Centro de Educação Permanente, com o objetivo de "propiciar recursos de apoio à educação formal e complemento ao processo educativo informal, de maneira a assegurar o desenvolvimento integral e harmônico da comunidade”. (CESARINO, 2006, p.29). Nas análises da autora, uma decisão aparentemente técnica, visando justificar a permanência da instituição na estrutura da Secretaria de Estado de Educação e contar com recursos financeiros mais significativos, mas que, sem dúvidas, foi tomada como ação política arbitrária, fruto da ditadura militar.

Em 1982 um novo espaço cultural foi instalado no "Centro de Educação Permanente Prof. Luiz de Bessa"; tratava-se da galeria de arte Paulo Campos Guimarães. Visando incentivar a produção de artistas iniciantes, inúmeras exposições realizadas ali apresentaram ao público trabalhos de grandes nomes do cenário das artes plásticas mineiro. Hoje, a galeria engloba entre suas funções divulgar datas e temas significativos para a literatura por meio de mostras e exposições itinerantes que, após apresentação na Biblioteca, circulam entre outras bibliotecas públicas do Estado.

No ano seguinte à fundação da Galeria, em 1983, a instituição retoma sua identidade e volta a receber o nome de Biblioteca Pública Estadual Luiz de Bessa. É nessa data que se dá a criação da Superintendência de Bibliotecas Públicas, com suas quatro diretorias: a própria Biblioteca; a Diretoria de Processamento Técnico; a Diretoria Metropolitana e a Diretoria de Assistência às Bibliotecas Públicas. Em 1994, por meio da Lei nº . 11.726, a Superintendência passou a coordenar o Sistema Estadual de Bibliotecas Públicas Municipais, cujas funções são: incentivar a criação, expansão e manutenção dos serviços bibliotecários no Estado; promover a articulação inter-regional das bibliotecas públicas através de uma rede de bibliotecas polos; capacitar o quadro de recursos humanos das bibliotecas públicas municipais; promover a 
implementação das novas tecnologias da informação adequadas ao armazenamento e gerenciamento de acervos; incrementar projetos culturais de estímulo à leitura no âmbito das bibliotecas públicas; e, manter atualizado o cadastro de bibliotecas públicas municipais.

No contexto desse conjunto de atribuições, a instituição orienta a criação de bibliotecas públicas municipais, a organização de seus espaços físicos e acervos, o desenvolvimento de associações de amigos da biblioteca e a elaboração de projetos culturais. Faz doações de livros para bibliotecas criadas e já em operação, além de oferecer cursos de capacitação para seus gestores. Por fim, se posta como intermediadora entre essas instituições e programas governamentais de apoio às bibliotecas públicas, principalmente aqueles financiados pela Fundação Biblioteca Nacional. Nos últimos anos, fomentou o projeto "Construindo uma Minas Leitora"', cujas ações objetivavam, prioritariamente, zerar o déficit de bibliotecas públicas nos municípios mineiros.

O desenrolar da década de 1990 pautou duas mudanças importantes no contexto da Biblioteca Pública Estadual. A primeira delas aconteceu em 1996, quando se concretizou a transferência de um rico acervo de revistas e jornais históricos, até então pertencentes ao Arquivo Público Mineiro, para seus fundos bibliográficos, ação que teve por consequência a criação da Diretoria da Hemeroteca Pública de Minas Gerais. Posteriormente, em 2003, os documentos em questão foram incorporados às Coleções Especiais da Biblioteca Pública. Processo finalizado em 2007, quando se processa a transferência total da Hemeroteca de sua antiga sede para o prédio da Praça da Liberdade. No cenário atual, seu fundo documental é composto de 1.206 títulos de jornais e 581 títulos de revistas.

A segunda mudança foi estrutural e aconteceu em 1998, quando a instituição recebe do governador Eduardo Azeredo a doação do antigo anexo da Secretaria da Fazenda, localizado na Rua da Bahia, entre a avenida Bias Fortes e a rua Gonçalves Dias. De acordo com Cesarino (2006, p.36), “o ato de transferência condiciona a ocupação do novo prédio, após sua reforma, à expansão da Biblioteca Luiz de Bessa". Tal condição resultou no Anexo Professor Francisco Iglésias, um prédio que permite à população passar da Rua da Bahia à Praça da Liberdade, através da pequena Praça Carlos Drummond de Andrade. No Anexo, funcionam o Setor de

\footnotetext{
${ }^{9}$ De acordo com informações fornecidas pelo Sistema Estadual de Bibliotecas Públicas de Minas Gerais, o programa Construindo uma Minas Leitura não mais é executado. O Edital Construindo uma Minas Leitora 2014 foi a última ação desse programa. A partir de 2016, o edital para estimular a criação de novas bibliotecas públicas no Estado passou a ser denominado simplesmente Edital de Criação de Bibliotecas Públicas Municipais. Em 2016 foram criadas 5 novas bibliotecas e, em 2017, o edital previu o apoio à criação de 3 bibliotecas. Ressalta-se que o abandono do nome Construindo uma Minas Leitora está diretamente vinculado à mudança na gestão política do Estado que se deu a partir das eleições de 2014.
} 
Empréstimo Domiciliar, com mais de 260.000 livros disponíveis, cobrindo as diversas áreas do conhecimento, com ênfase em literatura brasileira e estrangeira e o Setor de Referências e Estudo, destinado ao atendimento de pesquisas gerais e a suprir às necessidades informacionais da população. Promove também diversas ações de incentivo e mediação à leitura com exposições temáticas, palestras e exibições de documentários. Há ainda, nesse espaço, a Sala de Pesquisa via Internet, um serviço gratuito que proporciona acesso à web por um período de 40 minutos diários.

Ações que, aliadas à diversidade e ao tamanho de seu acervo - aproximadamente 570 mil exemplares -, ao conjunto dos serviços que presta à população, sua localização no Circuito Cultural da Praça da Liberdade e à quantidade de usuários que constantemente a ela recorrem - cerca de 300 mil por ano -, nos permitem afirmar a importância que a Biblioteca Pública Estadual de Minas Gerais ${ }^{10}$ ocupa no cenário sociocultural de Belo Horizonte e do Estado como um todo. Importância que pode ser mensurada tanto pelos modos como a Biblioteca dinamiza a vida intelectual da cidade, preservando vestígios importantes da memória coletiva dos belorizontinos e mineiros, por se constituir em espaço de acesso público à informação e ao conhecimento, por sua preocupação com a dinamização das práticas de leitura e educação tanto na capital como em outras partes do Estado, por propiciar experiências de sociabilidade e enraizamento, e, também, pela presença que a mesma marca na história de vida de seus usuários. Histórias de vida que, por sua vez, se convertem em objeto de análise de nossa próxima seção.

\section{A Biblioteca Pública Estadual de Minas Gerais vista por seus usuários: experiências de vida e memórias afetivas}

Para além dos dados acima apresentados, a importância da Biblioteca Pública Estadual e os modos como ela se insere na paisagem sociocultural dos mineiros podem ser revelados, também, pelo testemunho de seus usuários, sobretudo quando estes são chamados a analisar os pontos que interconectam sua história de vida à história dessa instituição. Atentando para tal potencialidade, a presente seção põe em evidência os depoimentos de quatro (4) sujeitos que, entre outros relatos, refletiram sobre três questões específicas: que impressões e sensações foram vivenciadas por eles durante o primeiro contato com a Biblioteca Estadual? Qual a importância da Biblioteca Pública para Belo Horizonte; e qual o lugar que essa instituição ocupa em suas histórias de vida? Visando reforçar essa dimensão testemunhal e tendo por referência

${ }^{10}$ Conforme já apontado, essa é a nova denominação da Biblioteca desde maio de 2017.

InCID: R. Ci. Inf. e Doc., Ribeirão Preto, v. 9, n. 1, p. 146-167, mar./ago. 2018. 
as dimensões metodológicas de uma pesquisa em história oral ${ }^{11}$, apresenta-se o perfil biográfico de cada um de nossos interlocutores, estratégia que nos ajudará a compreender melhor o nível de relações mantidas por eles com os espaços, coleções, serviços e sujeitos que mobilizam o dia-a-dia dessa unidade bibliotecária, acenando, assim, para outras tantas modalidades de inserção social da Biblioteca Pública Estadual.

Seguindo nessa direção, faz-se necessário ressaltarmos que, ao adotar como foco de suas preocupações "experiências vividas" e tomá-las como dinâmicas da experiência pessoal ancoradas em processos de socialização coletiva, a história oral constitui-se em método de pesquisa capaz de recompor visões de mundo, padrões de comportamento e modos de apreensão do cotidiano que geralmente não estão registrados em outros tipos de fontes. Mais que isso, ao converter narrativas mnêmicas individuais em elemento central do processo de reconstituição de épocas, acontecimentos e parâmetros normativos relevantes para a vida do grupo ao qual o depoente se insere, bem como das instituições e movimentos aos quais o sujeito da recordação se manteve vinculado, esse mecanismo de elaboração discursiva também empreende "um esforço voltado para a expressão da pluralidade de visões inerentes à vida coletiva". (DELGADO, 2006, p.50).

Não sem razão a história oral tem sido recorrentemente empregada em estudos que se propõem a: recuperar memórias locais, comunitárias, regionais, étnicas, de gênero, nacionais, entre outras, sob diferentes óticas e versões; reconstruir evidências históricas, culturais, políticas e sociais via conjunção de inúmeros depoimentos; recompor informações sobre acontecimentos e processos que não se encontram registrados em outros tipos de documentos, ou mesmo que, estando registrados, não se fazem disponíveis nem para pesquisadores e nem ao público geral por diferentes razões; contemplar o registro de visões de personagens ou testemunhas da história que nem sempre são validados pela denominada história oficial; bem como por aqueles que intentam possibilitar a associação entre acontecimentos da vida pública e da vida privada, por meio de narrativas individuais ${ }^{12}$. Atentando para esse conjunto de possibilidades, sintetizamos abaixo os relatos elaborados por nossos entrevistados conferindo

\footnotetext{
11 Adotamos, pois, como premissa que a história oral constitui-se em um conjunto de procedimentos metodológicos que buscam registrar, através de narrativas induzidas e do entrecruzamento com fontes históricodocumentais, "testemunhos, versões e interpretações sobre a História em suas múltiplas dimensões: factuais, temporais, espaciais, conflituosas, consensuais. Não é, portanto, um compartimento da história vivida, mas, sim, o registro de depoimentos sobre essa história vivida". (DELGADO, 2006, p.15-16 - itálicos do autor).

${ }^{12}$ Para a constituição de um quadro mais amplo dos estudos que podem ser desenvolvidos a partir da história oral conferir: ALBERTI (2004), DELGADO (2006), FERREIRA \& AMADO (2006); MEIRY (1994 e 2007), THOMPSON (1992), WORCMAN \& PEREIRA (2006), entre outros.
} 
visibilidade aos pontos que interconectam suas histórias de vida à história da Biblioteca Pública Estadual.

Nossa primeira usuária chama-se Iara S., é natural de Belo Horizonte e nasceu em 1988. Sempre morou com os pais, os avós maternos e sua única irmã. Graduou-se em história e trabalha como técnica em assuntos educacionais na Universidade Federal de Minas Gerais/UFMG. Afirma que cresceu rodeada por livros, embora a biblioteca familiar não fosse muito grande. Um dos primeiros livros que leu foi a coleção do "Sítio do Pica-pau Amarelo", presente dado por uma tia: "os livros eram grandes, não eram fininhos e eu lia várias vezes o mesmo livro. (IARA S., p.2). Além das aventuras do Sítio, sua infância foi marcada pelas leituras das "Revistinhas da Turma da Mônica", já que a irmã havia ganhado uma assinatura da madrinha.

Diz com orgulho que sempre estudou em escolas públicas e que, quando foi para o jardim de infância, já sabia ler. Apesar das escolas onde estudou possuírem bibliotecas, relata que, até a adolescência, o espaço de leitura mais importante para ela foi a Biblioteca Pública Infanto-Juvenil de Belo Horizonte ${ }^{13}$. Seu pai possuía uma oficina nas imediações e, às vezes, ela e a irmã passavam o dia todo na Infanto-Juvenil. Foi ali que descobriram os livros da

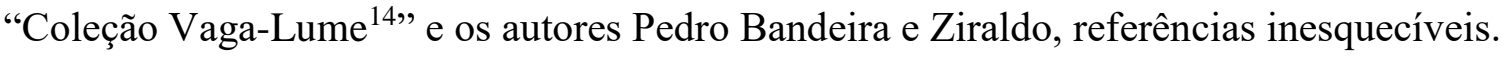

Quando se tornou adolescente e seus interesses mudaram, migrou para a Biblioteca Estadual. Ia para lá estudar e se preparar tanto para o vestibular quanto para alguns concursos públicos que havia programado realizar. Sua chegada à Biblioteca é descrita como um momento de puro encantamento e permeado por uma persistente vontade de se integrar àquele espaço, bem como se apropriar dos livros ali disponíveis. Em suas palavras:

Eu fiquei completamente..., assim: "nossa, o quê que eu vou querer ler hein?”. Aí eu fui descobrindo... Então eu fiquei assim: "nossa é livro demais como é que eu vou descobrir o quê que é romance, o quê que não é? O quê que é poesia, o quê que não é?". Aí eu saí meio que fuçando e fui descobrindo aos poucos, mas a primeira impressão foi de muito encantamento. Eu tinha a ilusão de, quando era nova, de que trabalhar na biblioteca devia ser a coisa mais maravilhosa do mundo. (IARA S., p.8).

Em função disso, achava o espaço "leve" e "tranquilo", "que não te dá nenhum sentimento de ir embora”. (IARA S., p.9). Para lá se dirigia quando desejava pegar um livro

\footnotetext{
${ }^{13}$ Embora possua um nome muito parecido, não se trata do mesmo espaço infanto-juvenil da Biblioteca Pública Estadual de Minas Gerais. A instituição mencionada por nossa entrevistada é mantida pela prefeitura de Belo Horizonte.

${ }^{14}$ A Série Vaga-Lume é uma coleção de livros lançada pela editora Ática a partir do ano de 1972. Suas obras, voltadas para o público infanto-juvenil, constituíram-se em um marco de vendagem no âmbito do mercado literário e livreiro do país.
}

InCID: R. Ci. Inf. e Doc., Ribeirão Preto, v. 9, n. 1, p. 146-167, mar./ago. 2018. 
emprestado, fazer trabalhos da escola ou usar a internet. Historiadora de formação, afirma que a biblioteca teve muita influência na escolha desse campo profissional. Ao ser perguntada por que, afirma em tom contundente:

Eu formei em história, mas eu não trabalho como historiadora, mas a minha escolha de curso, o que eu ia fazer na vida, tem muito a ver porque é curso de gente que gosta de ler, sabe? Eu gostava muito de história na época e procurava livros que tivessem..., a biblioteca estimulava e nutria a minha sede de ler. Então tem um papel muito importante porque era o lugar que eu encontrava os livros que eu queria ler. Então, se não fosse isso eu sei lá qual caminho eu ia seguir na vida, mas acho que não seria nada de humanas sabe? (IARA S., p.13).

Importância que, em sua concepção, se estende para o cenário da cidade como um todo, sobretudo em termos de atividades voltadas à promoção da leitura. Não sem razão, ao ser perguntada sobre a relevância da biblioteca para Belo Horizonte, Iara S. tece a seguinte reflexão:

Nossa, eu acho que é enorme! Posso estar falando besteira, mas eu acho que é a maior biblioteca pública que a gente tem aqui! Então eu acho que é enorme, enorme o papel que ela tem a cumprir. [...] Tem pessoas que dizem que o "brasileiro não gosta de ler", aí você oferece o bem público para as pessoas. [...] Então eu acho que o papel dela é muito importante na cidade, no cenário da cidade mesmo. (IARA S., p.14-15).

Modalidade de compreensão que, como veremos, também foi ressaltada por nosso segundo depoente. Luiz Q. é natural de Carangola. Licenciou-se em letras pela Universidade Federal de Minas Gerais, onde também obteve os graus de mestre e doutor em Estudos Literários. Nasceu em 1964 e é o sétimo filho de um total de nove irmãos. Seu pai era funcionário público e a mãe professora primária. Sua iniciação literária se deu através dos livros da "Série Vaga-Lume". Depois, passa a ler desordenadamente tudo que "caía em suas mãos". Mesmo tendo aprendido a ler muito cedo, não frequentava a biblioteca de sua escola porque, segundo ele, "não havia estímulo para isso". Situação semelhante ao que aconteceu com a biblioteca pública de Carangola, "um espaço pequeno e que não funcionava com regularidade". (LUIZ Q., p.03).

Afirma não se lembrar do primeiro livro que leu, mas se recorda de ter sido um presente ofertado por algum familiar para amenizar uma doença que havia contraído quando criança. Adverte que o mesmo tinha mais gravuras que texto, o que o levou a lê-lo e relê-lo várias vezes. Dessa fase, não se esquece da descoberta do "Círculo do Livro" ${ }^{15}$ ", que considera o elemento desencadeador de sua compulsão por comprar livros:

\footnotetext{
${ }^{15}$ Editora que vendia suas obras por meio de um "sistema de clube", onde a pessoa era indicada por algum sócio e, a partir disso, recebia uma revista quinzenal com dezenas de títulos a serem escolhidos. O novo sócio teria então
} 
Eu me lembro que eu comprava livros pelo Círculo do livro, eu recebia a revista, escolhia e, na medida do possível, eu ia comprando por meio de pedido. Eu pedia o meu pai ou minha mãe ou então meu avô que tinha uma loja de fotografias. Eu ficava lá com ele, ajudava ele e ele me dava um dinheiro e esse dinheiro eu usava para fazer os pedidos do Círculo do livro (LUIZ Q., p.07).

Luiz Q. mudou-se para Belo Horizonte quando completou 18 anos, veio prestar vestibular. Quanto à Biblioteca Pública, a mesma só passa a ser uma referência importante para o depoente no momento da transferência da Hemeroteca para seus fundos documentais. Isso porque, o mesmo procura em jornais e revistas antigos informações que possam subsidiar seu trabalho de pesquisa sobre os espaços de sociabilidade LGBT em Belo Horizonte, especialmente entre as décadas de 1940 e 1980. Já publicou um livro sobre o assunto e pretende escrever outras duas obras. Mantém contato com a instituição há mais de dez anos e, ultimamente, tem ido até lá pesquisar todas as sextas-feiras. Desse contato constante com a instituição, Luiz Q. assinala que: “ao longo desse tempo, passaram pelas minhas mãos todos os jornais desde 1950 até a década de 70 e tô começando a década de 80. Então trinta anos eu já peguei, já folheei um a um, dia a dia, mês a mês, ano a ano pra buscar essas informações" (LUIZ Q., p.02).

Para ele, a imagem que sintetiza sua chegada à Biblioteca Estadual é a de uma pungente frustração: o prédio era mal cuidado, havia pouco espaço para leitura e quase nenhum investimento público na manutenção de seus setores e acervos. Com o passar dos anos visualiza uma mudança de perspectiva e, em seu discurso, referenda a importância social da instituição para Belo Horizonte, bem como em sua própria trajetória de vida. Estabelecendo um contraponto com as bibliotecas universitárias, o depoente reforça seu caráter de instituição pública e ressalta a variedade dos acervos ali disponíveis como marco de fundamental relevância para a cidade e o Estado:

\begin{abstract}
A Biblioteca é fundamental na cidade. Ela é a única biblioteca, até onde eu sei, aberta ao público com um acervo variado, não só de livros, mas também de jornais e de revistas. Você tem as bibliotecas universitárias, mas elas acabam não atendendo à mesma função que uma biblioteca pública deveria atender. Então eu acho que é fundamental, ela precisa existir, ela precisa continuar existindo (LUIZ Q., p.14).
\end{abstract}

Precisa continuar existindo não só em função da amplitude de seus acervos ou pela diversidade de seus serviços, mas, sobretudo, pela importância que ela possui seja no nível social ou no contexto da história de vida de seus leitores e usuário. Para Luiz Q. o contato com essa instituição foi tão relevante que o trabalho de pesquisa na Hemeroteca resultou em uma

a obrigação de comprar ao menos um livro no período. Embora essa estratégia comercial tenha rendido bons lucros, a editora encerrou suas atividades no final da década de 1990. 
sensível mudança na sua maneira de ler jornal e isso impactou diretamente na forma como hoje pensa o jornalismo, área de conhecimento em que atua profissionalmente. Dito em suas próprias palavras:

\begin{abstract}
O manuseio dos jornais na hemeroteca acabou também mudando a minha forma de ler o jornal. Mudou no sentido, assim, ler dez, vinte, trinta anos de jornais..., você acaba criando alguns mecanismos internos de reflexão, de ver como que o jornal vai mudando ao longo do tempo, não só na sua diagramação, mas na forma de trabalhar as informações, na forma de dar atenção a determinados temas ou a determinadas áreas. Enfim, isso acaba te levando a pensar em como que o jornal tá presente na sua vida, como que o jornal acaba te conduzindo a pensar de certa forma, acaba guiando uma forma de ler que você não tem, por exemplo, com o livro, com a obra literária. Então isso também foi importante. Ganhar essa consciência na frequência cotidiana à hemeroteca foi importante também pra me fazer pensar sobre o jornalismo (LUIZ Q., p.16).
\end{abstract}

Foi importante também para que nosso interlocutor pudesse tecer novas redes de sociabilidade. Luiz Q. não diz que aquele espaço é como sua casa, mas que, de tanto frequentálo, adquiriu tamanha familiaridade que acabou despertando um sentimento, uma atenção diferente para com ele. Em suas recordações, a Biblioteca ganha feições de um lugar especial porque, conforme ressalta, consegue perceber sua própria história de vida, tal qual sua trajetória de formação intelectual se refletindo na história da instituição e nas relações mantidas com os funcionários que ali trabalham. Ao fim de seu depoimento, eis o que ele nos declara:

Enfim, eu não direi, eu não chegaria ao exagero de dizer que a biblioteca é a minha casa. Não é! Esse tipo de metáfora pra mim é muito exagerada, mas hoje eu possuo certa familiaridade com ela. Por exemplo, seu Milton, que é um dos porteiros que se revezam ali na portaria, ele me cumprimenta pelo nome, eu o cumprimento pelo nome também, aí quando eu chego no balcão pra pegar a chave pro escaninho a Helena me cumprimenta pelo nome. Quando eu subo, o Jairo, o Marcos, a própria Eliani ... Atualmente a Priscila que é a responsável pela hemeroteca, antes era a Marina, antes da Marina era a Tais, antes da Tais era uma que não sei o nome, mas mesmo que eu não saiba o nome dela, cria-se essa espécie de história da instituição, mesmo que seja uma história particular a partir do contato semanal que eu tenho com a instituição, por meio dessa certa familiaridade de construir uma história minha lá dentro e ver um certo reconhecimento, um certo carinho que eles têm comigo, isso sem dúvida é muito importante e agradável pra mim (LUIZ Q., p.16).

Possibilidades de interação com a Biblioteca Pública que também fez toda a diferença na história de vida de nosso terceiro interlocutor. Natural de São José dos Campos, São Paulo, e nascido em 1986, Luiz R. veio para Belo Horizonte aos doze anos. Filho de pais leitores, acredita ter sido deles que herdou o gosto pela leitura. Aos cinco anos começou a ser alfabetizado pela irmã e passou a se interessar por diversos assuntos literários. Gosta de teatro, exposições, museus e cinemas, só não se sente confortável em lugares muito tumultuados em razão de sua deficiência visual. Luiz R. é portador de um problema congênito na retina e possui 
apenas $10 \%$ da visão, consegue andar sem o auxílio de bengala durante o dia, mas, à noite, não mostra a mesma autonomia na locomoção.

Tem uma afeição muito particular pela Praça da Liberdade, espaço que transita desde que chegou a Belo Horizonte. No entanto, não foi a Praça que o levou até à Biblioteca Pública. Esse contato só se deu quando o depoente já havia completado 22 anos e estava cursando o $5^{\circ}$ período de Direito. À época, enfrentava dificuldades para ler os textos trabalhados em sala de aula e estava praticamente decidido a abandonar o curso. Tomou conhecimento do setor Braille da instituição por meio do irmão (também deficiente visual), mas só teve coragem de se dirigir até lá passado um mês da primeira conversa sobre o assunto. Chegou à Biblioteca se sentindo deslocado e achando aquilo tudo muito esquisito, mas mesmo assim marcou uma leitura voluntária para o dia seguinte. O que aconteceu? Eis a sua resposta:

É difícil essa readaptação, para mim foi muito difícil, em um dia eu estudo normalmente e no outro dia eu estou aqui para as pessoas lerem para mim? Ou seja, já tinha parte da minha autonomia tolhida, né!? Eu marquei voluntário, aquilo foi uma coisa esquisita, eu não consegui compreender bem o que ele leu, foi um estudo meio..., foi algo muito desconfortável, estranho, diferente, era o novo. Mas eu lembro que com uma semana eu já estava completamente adaptado e apaixonado com os voluntários, muito integrado, me sentindo acolhido. (LUIZ R., p.6-7).

Acolhimento e readaptação, ações integradoras que permitiram ao nosso entrevistado concluir o curso de graduação em direito, passar em dois concursos públicos, aprender latim e criar vínculos afetivos estreitados por relações sócio-afetivas mantidas tanto com os bibliotecários, quanto com os voluntários do setor. O depoente assim descreve a importância dessas novas relações ali estabelecidas:

\footnotetext{
Meu vocabulário não tem palavras para descrever como é essa relação. Grande parte dos meus amigos verdadeiros vieram daqui. Com relação aos bibliotecários, também são pessoas que eu vou levar no meu coração pelo resto da vida, são pessoas que fazem parte da minha história. Eu sou muito grato a este setor, não só pela leitura que eu recebo, não só pela ajuda física que eu recebo, mas também por saber que aqui é um lugar de pessoas especiais. O dia que eu não puder mais frequentar este setor, eu vou lembrar disso aqui como um período maravilhoso na minha vida. As experiências, a maturidade que eu adquiri aqui, eu aprendi muita coisa, eu mudei muito como pessoa, tive muita experiência. Eu devo pouco do que eu sou a esse setor aqui. (LUIZ R., p.7).
}

Após um pequeno instante de silêncio, o usuário retoma sua narrativa e reforça ainda mais o lugar que a Biblioteca ocupa hoje em sua vida e a importância que a mesma possui para a cidade:

Você já deve ter percebido que é algo muito importante pra mim. O dia que eu não puder mais vir aqui realmente vai ser lamentável, eu vou lembrar disso aqui com muito carinho. Igual eu te falei, hoje eu sou adaptado com computador e a lupa eletrônica, eu consigo ter certa autonomia para estudar e eu já dou conta de estudar sem o auxílio 
do voluntário, mas esse período em que eu tinha 22 anos e no qual eu descobri o setor Braille, foi crucial porquê do sétimo período até o décimo os voluntários me carregaram no colo pra eu chegar até lá. Com isso eu pude perceber que, às vezes o que impede determinados deficientes de alçarem voos mais altos na vida é realmente não ter este aparato aqui, por que às vezes o deficiente visual que está lá na casa dele, que não conhece o setor braille, ele perde muito, ele demora muito para absorver certas informações que aqui ele teria mais rápido. [...] E assim, eu acho que o setor braille é muito importante sim no sentido de integração dos deficientes visuais e maior inferência por parte das pessoas que enxergam sobre a realidade dos deficientes visuais, como que os deficientes visuais levam, conduzem suas vidas. (LUIZ R., p.9).

Assim como para Luiz R., a Biblioteca Pública também representa um lugar de transformação na história de vida de nosso quarto depoente. José J. nasceu em 25/09/1969, na cidade de Pitangui. Mudou-se para Belo Horizonte quando tinha dois anos de idade. Hoje é casado, pai de duas meninas e tornou-se professor universitário. É também escritor, coordenador de projetos culturais, tendo integrado por vários anos a Comissão Municipal de Incentivo à Cultura. Relata que os pais não tiveram acesso à leitura, mas que sempre se esforçaram para que os filhos estudassem. Os poucos livros existentes em sua casa eram do irmão mais velho. Em seu trabalho de reminiscência, afirma categoricamente que o evento que mais influenciou sua formação enquanto leitor foi a descoberta, na $5^{\mathrm{a}}$ série, do "caminhãobiblioteca" da Biblioteca Pública, "a experiência efetiva com a literatura veio somente a partir dessa possibilidade que apareceu quando a mulher do caminhão-biblioteca chegou na minha escola falando - "quem quiser pode fazer a carteirinha do caminhão-biblioteca, tá na praça da igreja”. (JOSÉ J., p.1-2).

Quando adolescente, não frequentava os espaços urbanos da cidade, "a minha família não tinha condições de ir a lugar nenhum”. (JOSÉ J., p.4). Talvez por isso a Praça da Liberdade sempre lhe pareceu um lugar de elite, que o constrangia. Perspectiva que também inclui o prédio da Biblioteca Pública: "eu não gostava do ambiente. O lugar não me..., não me deixava muito..., muito tranquilo". (JOSÉ J.; p.5). Sendo assim, seu contato com a instituição se deu mesmo por meio do carro-biblioteca, espaço que lhe ajudou a redimensionar suas perspectivas de vida e, posteriormente, a estabelecer outros vínculos com a própria instituição.

Vínculos estreitados não só porque nosso entrevistado se tornou professor e pesquisador acadêmico ou um consultor para políticas públicas, mas porque a relação com o carro-biblioteca acabou por se reverberar em outros campos de sua vida. "E essa relação que.., que depois eu recuperei é que me faz entrar hoje com certo grau de tranquilidade naquele lugar”. (JOSÉ J., p.14). Autoanálise que deixa transparecer nas reminiscências de nosso depoente o reconhecimento da Biblioteca Pública como importante marco de ancoragem de suas experiências pessoais. 
Transpondo essa dimensão intersubjetiva, José J. também analisa a importância da Biblioteca Pública para Belo Horizonte e o Estado, ressaltando que:

\begin{abstract}
Viajando pelo interior para a implementação do sistema nacional de cultura, as pessoas falam com uma... com uma aura da biblioteca pública estadual. É como se ela fosse a biblioteca central do estado. Então, nesse sentido, a biblioteca tem uma..., tem um papel político importante no estado. É a referência no estado de Minas Gerais, o papel político da biblioteca pública é fundamental no estado inteiro. (JOSÉ J., p.1112).
\end{abstract}

Dito isso, e como pode ser observado em todos os depoimentos apresentados, cada um de nossos interlocutores reconhece a importância que a Biblioteca Pública Estadual de Minas Gerais possui em suas histórias de vida, para a cidade e, em ampla medida, para o Estado. Indo mais além e aproximando esses depoimentos à contextualização histórica traçada na seção anterior, alguns pontos responsáveis por definir o lugar que essa instituição ocupa na paisagem cultural da cidade, bem como suas dinâmicas de inserção social puderam ser desvelados. $\mathrm{O}$ primeiro deles acena para sua importância enquanto lugar de leitura, de educação, lazer e sociabilidade. Somam-se a esses enquadramentos a compreensão de que a Biblioteca Estadual desempenha importante trabalho de conservação, organização e disseminação da memória, do patrimônio cultural e intelectual belo-horizontino, assim como da história mineira e nacional. Conjugados à diversidade de seus acervos e sua localização no Circuito Cultural da Praça da Liberdade, tais indicativos referendam a importância que a Biblioteca Pública Estadual ocupa no cenário sociocultural de Belo Horizonte, dinamizando a vida intelectual da cidade e preservando vestígios importantes da história, da cultura e dos substratos representacionais tanto da identidade intersubjetiva de seus usuários, quanto da cidade e do estado de forma mais ampla.

Nesses termos, essa conjunção entre testemunhos vivenciais e recomposição histórica emerge como dispositivo analítico altamente promissor quando o que se quer apreender é a importância social das bibliotecas públicas - seja de modo genérico e abrangente ou, de forma mais restrita, de uma biblioteca pública específica - e a forma como elas atravessam a história de vida dos sujeitos que as frequentam. Tecemos mais algumas análises acerca dessas possibilidades nas considerações abaixo. 


\section{Considerações finais}

O presente artigo centra suas discussões em torno de dois objetivos específicos: compreender qual o lugar ocupado pela Biblioteca Pública Estadual de Minas Gerais no cenário cultural e intelectual de Belo Horizonte; e, em paralelo a isso, apreender em que medida a apropriação de seus acervos e serviços, bem como as dinâmicas de sociabilidade experienciadas em seus espaços marcam a história de vida dos usuários que a ela recorrem. A partir dos relatos colhidos e do percurso historiográfico assinalado, tornou-se possível explicitar algumas funções sociais recorrentemente acionadas para demarcar a importância da Biblioteca Pública Estadual no contexto de Belo Horizonte, do Estado e na história de vida dos nossos depoentes.

Como síntese dos resultados, ressalta-se a forte presença da Biblioteca Pública Estadual nas histórias de vida dos nossos depoentes e o seu reconhecimento como instituição dinamizadora do cenário cultural e intelectual da cidade de Belo Horizonte. Importância que se revela através da extensão e da diversidade de suas coleções; do potencial congregador dos serviços, ações e atividades que oferece; da responsabilidade que assume nos processos de fomento à leitura, à educação e à preservação do patrimônio e da memória local, regional e nacional; no suprimento às demandas por espaços de estudo e sociabilidade; enfim, em sua força de representação política, histórica e cultural.

Força de representação que não anula os embates políticos e as lutas sociais. Nesse sentido, a Biblioteca é também um espaço onde os conflitos, as contradições, os paradoxos e as distorções de força que perpassam as interações entre os sujeitos e a sociedade se condensam e fazem-se perceptíveis. Não é por acaso, pois, que a ideia de biblioteca como espaço de segregação também foi evocada. Contudo, não podemos nos esquecer que estamos falando da maior biblioteca pública do estado, uma instituição que, apesar de seus paradoxos e contradições, interfere diretamente no contexto social em que se insere e até para além dele, viabilizando a formação de novos acervos pelo interior de Minas e promovendo cursos de capacitação para bibliotecários e não bibliotecários da grande maioria dos municípios. Por tanto, não é sem razão que nossos entrevistados, em vários momentos de suas falas, expressamse em relação à instituição de maneira carinhosa, pontuando a importância dela em suas biografias e defendendo sua valorização social.

Valorização social que nos impele a reconhecê-la como um dos equipamentos culturais mais importantes da cidade de Belo Horizonte e, de modo extensivo, também do Estado. Certamente parte dessa importância está vinculada à imponência do seu projeto arquitetônico, 
à sua localização no Circuito Cultural da Praça da Liberdade e aos números superlativos de suas coleções, elementos que congregam em torno de si todo um conjunto de indícios e referências simbólicas que acabam por desvelar certos modos de atuação responsáveis por inserir todo um contingente populacional em um plano mais amplo da cultura, da história e da memória. Qualificadores que se mostram potencializados quando a eles somamos a grande presença que a Biblioteca Pública Estadual de Minas Gerais marca nos discursos e memórias que atravessam e sustentam as histórias de vida de cada um de seus usuários.

Por fim, faz-se importante assinalarmos que dentre os vários caminhos possíveis de se trilhar quando o que se almeja é demarcar as dinâmicas de inserção e a importância social de determinada biblioteca pública, o presente trabalho recorre às proposições metodológicas dos estudos em história oral por considerar que a produção de fragmentos discursivos de ordem intersubjetiva ao serem conjugados a indícios documentais representa avanço significativo frente aquelas análises que se fundamentam prioritariamente em dados de natureza quantitativa, tipo relatórios de empréstimos e de pesquisa, índices de usabilidade do acervo ou gráficos que apontam o aumento e/ou a redução dos números de usuários de uma dada instituição. Premissa que poderá ser comprovada ou negada em estudos futuros.

\section{Referências}

ALBERTI, Verena. Ouvir contar: textos em história oral. Rio de Janeiro: FGV, 2004.

BARRETO, Abílio. A origem da bibliotheca pública. Boletim Bibliographico, Bello Horizonte, anno 1, n.1, p.5-7, set. 1935.

BRETTAS, Aline Pinheiro. A biblioteca pública de Belo Horizonte: o legado cultural de uma sociedade literária. Inf. Inf., Londrina, v.15, n.02, p.93-108, jul./dez. 2010.

CESARINO, Maria Augusta da Nóbrega (Org.). Biblioteca pública estadual Luiz de Bessa: 50 anos de cultura. Belo Horizonte: Secretaria de Estado de Cultura de Belo Horizonte : Superintendência de bibliotecas públicas, 2006.

DELGADO, Lucilia de Almeida Neves. História oral: memória, tempo, identidades. Belo Horizonte: Autêntica, 2006. (Leitura, escrita e oralidade).

FERREIRA, Marieta de Moraes; AMADO, Janaina (Orgs.). Usos e abusos da história oral. 8. ed. Rio de Janeiro: FGV, 2006.

MEIRY, José Carlos Sebe Bon. Definindo história oral e memória. Cadernos CERU, n.5, série 02, 1994, p.52-60.

MEIRY, José Carlos Sebe Bon; HOLANDA, Fabíola. História oral: como fazer, como pensar. São Paulo: Contexto, 2007. 
MINAS GERAIS. Assembléia Legislativa de Minas Gerais. Lei n. 1087, de 02 de jun. 1954. Cria a Biblioteca Pública de Minas Gerais e dá outras providências. Disponível em: <https://www.almg.gov.br/consulte/legislacao/completa/completa.html?tipo=LEI\&num=1087

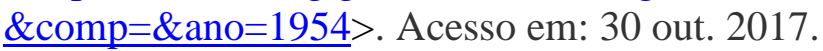

MINAS GERAIS. Assembléia Legislativa de Minas Gerais. Lei no 11.726, de 30 de dez. de 1994. Dispõe sobre a política cultural do Estado de Minas Gerais. Disponível em: http://www.siam.mg.gov.br/sla/download.pdf?idNorma=2292, Acessado em: 30/10/2017.

OSWALDO, Angelo. A Biblioteca Pública Estadual ganha novo nome para reforçar suas raízes mineiras. Superintendência de Bibliotecas Públicas e Suplemento Literário de Minas Gerais: Belo Horizonte: 2017. Disponível em:

http://www.bibliotecapublica.mg.gov.br/index.php/pt-br/noticias/240-biblioteca-publicaganha-novo-nome-para-reforcar-suas-raizes-mineiras, Acessado em: 28/07/2017.

PAULA, João Antônio de. 40 anos da Coleção Mineiriana. Suplemento Literário de Minas Gerais, Belo Horizonte, Secretaria do Estado de Cultura, dez., 2009, p.13-19. (Edição especial Coleção Mineiriana).

SILVEIRA, Fabrício José Nascimento da. Biblioteca pública, identidade e enraizamento: elaborações intersubjetivas ancoradas em torno da Luiz de Bessa. 2014. Tese (Doutorado em Ciência da Informação) - Escola de Ciência da Informação da Universidade Federal de Minas Gerais, Belo Horizonte, 2014.

SISTEMA ESTADUAL DE BIBLIOTECAS PÚBLICAS DE MINAS GERAIS. (sistema.sub@cultura.mg.gov.br). Construindo uma Minas Leitora [mensagem pessoal]. Mensagem recebida por fabrisilveira@gmail.com em 18/01/2018.

THOMPSON, Paul. A voz do passado. Rio de Janeiro: Paz e Terra,1992.

WORCMAN, Karen; PEREIRA, Jesus Vásquez (Coords.). História falada: memória, rede e mudança social. São Paulo: SESC-SP : Museu da Pessoa : Imprensa Oficial, 2006.

\section{Fontes}

Luiz Q. Belo Horizonte, Brasil, 10 jun. 2013, áudio. Entrevista concedida a Fabrício José Nascimento da Silveira para a realização da tese de doutorado intitulada Biblioteca pública, identidade e enraizamento: elaborações intersubjetivas ancoradas em torno da Luiz de Bessa. 18 páginas de transcrição.

José J. Belo Horizonte, Brasil, 19 jun. 2013, áudio. Entrevista concedida a Fabrício José Nascimento da Silveira para a realização da tese de doutorado intitulada Biblioteca pública, identidade e enraizamento: elaborações intersubjetivas ancoradas em torno da Luiz de Bessa. 15 páginas de transcrição.

Luiz R. Belo Horizonte, Brasil, 29 jun. 2013, áudio. Entrevista concedida a Fabrício José Nascimento da Silveira para a realização da tese de doutorado intitulada Biblioteca pública, identidade e enraizamento: elaborações intersubjetivas ancoradas em torno da Luiz de Bessa. 11 páginas de transcrição.

Iara S. Belo Horizonte, Brasil, 19 set. 2013, áudio. Entrevista concedida a Fabrício José Nascimento da Silveira para a realização da tese de doutorado intitulada Biblioteca pública, identidade e enraizamento: elaborações intersubjetivas ancoradas em torno da Luiz de Bessa. 16 páginas de transcrição. 